This item was submitted to Loughborough's Research Repository by the author.

Items in Figshare are protected by copyright, with all rights reserved, unless otherwise indicated.

\title{
A case study investigating the impact of the London 2012 Olympic and Paralympic Games on participation in two non-traditional English sports, Judo and Fencing
}

\section{PLEASE CITE THE PUBLISHED VERSION}

http://dx.doi.org/10.1080/02614367.2015.1035314

\section{PUBLISHER}

Routledge (@ Taylor \& Francis Group)

\section{VERSION}

AM (Accepted Manuscript)

\section{PUBLISHER STATEMENT}

This work is made available according to the conditions of the Creative Commons Attribution-NonCommercialNoDerivatives 4.0 International (CC BY-NC-ND 4.0) licence. Full details of this licence are available at: https://creativecommons.org/licenses/by-nc-nd/4.0/

\section{LICENCE}

CC BY-NC-ND 4.0

\section{REPOSITORY RECORD}

Pappous, Athanasios, and Emily Hayday. 2019. "A Case Study Investigating the Impact of the London 2012 Olympic and Paralympic Games on Participation in Two Non-traditional English Sports, Judo and Fencing". figshare. https://hdl.handle.net/2134/25490. 
Note: This is a pre-print version. The final version of the article with tables included can be found at the publishers' website: http://www.tandfonline.com/doi/abs/10.1080/02614367.2015.1035314?journalCode=rlst20

Citation: Pappous A., Hayday E. (2015). A case study investigating the impact of the London 2012 Olympic and Paralympic Games on participation in two non-traditional English sports, Judo and Fencing. Leisure Studies, 1-17.

\title{
A Case Study Investigating the Impact of the London 2012 Olympic and Paralympic
} Games on Participation in Two Non-Traditional English Sports, Judo and Fencing.

\begin{abstract}
The hosting of the London 2012 Olympic and Paralympic Games (LOPG) brought with it detailed legacy plans aiming to 'Inspire a Generation'. The idea that hosting a sports megaevent will encourage the host population to engage in more physical activity (PA), is commonly used by governments to justify the large investments they made (Frawley and Cush, 2011). The aim of this research paper was to investigate the impact that hosting the 2012 Games had on grass-root sports participation within the host nation. This paper focuses on two non-traditional English sports, Fencing and Judo and investigated the changes in mass sports participation. The membership rate analysis of our sample highlighted an overall increase in participation between 2007-2013, in both Judo and Fencing. The data gathered from the interviews with the head office staff at the National Governing Bodies (NGB's) and local club coaches suggested that the grass-root participation programmes were the most effective way of increasing participation, rather than the reliance, solely on the inspiration effect from hosting the LOPG itself. Finally, the study highlighted the importance of strengthening communication between local voluntary clubs and the NGB, to ensure sports could promote themselves and capitalise on this global sporting phenomenon, which provided unprecedented media coverage and opportunities for these non-traditional sports. This case study provides initial results relating to the effect that a major international multi-sport event can have in the development of non-popular sports in the host population, in terms of membership variations, participation programmes and organisational dynamics.
\end{abstract}

\section{Key words}

London 2012 Olympic and Paralympic Games; Grass-root Participation; Judo; Fencing and Non-traditional Sport, Legacy.

\section{Introduction}




\section{A. S. Pappous and E. J. Hayday}

Sports Participation, Mega-Events and Legacies

'Legacy is probably one of the most over used and misunderstood words' stated Lord Seb Coe in the commemorative Olympic anniversary series 'Inspire' (BBC One, 2013). Undoubtedly, the memories of London 2012 will live on, but more importantly will the anticipated participation legacy? We all know that the modern Olympic and Paralympic Games hold the highest profile globally, as a sporting event and it attracts a multitude of media and public attention. Yet, Girginov and Hills (2008, p.2092) state that the level of social, political and economic acquisition generated by the prospect of the LOPG even preBeijing 2008 was truly unprecedented.

A report published in 2008 by the Department of Culture, Media and Sport ([DCMS], Great Britain, 2008) outlines the five legacy promises that were made by the UK Government. This study will specifically focus on the sporting legacy (Promise 1), to make the UK a worldleading sporting nation (DCMS, 2008, p.16). The aim was to 'Inspire a Generation' through sport, the initial ambition was outlined in the Legacy Action Plan in June 2008, by the UK Labour Government with the objective of getting two million people more active by 2012 (Parliament Website, 2014). In early 2011, this pledge was quietly reduced to 1 million. Moreover, Jeremy Hunt, the then Olympics secretary, admitted that this key legacy aim would be scrapped altogether (Gibson, 2011). This resulted in the creation of the LOPG final participation legacy pledge, which proposed that all 5 to 16 year olds in England should participate in 5 hours of sport a week and 16-19 year olds should undertake at least 3 hours a week (DCMS, 2008, p.5). In late 2011, less than a year till the opening ceremony of the 2012 Games, 'Places, People, Play' was launched by the UK Government, as the main sports legacy programme for the LOPG.

Legacy has many suggested meanings, Gratton and Preuss (2008) defined the term as 'planned and unplanned, positive and negative, tangible and intangible structures created through a sport event that remain after the event'. Regarding these structures and the ability to quantify Olympic and Paralympic success for the host city, Cashman (2002, p.7) suggested that benefits are 'virtually impossible' to identify as they are 'vague and typically uncosted and their value inflated'. Additionally, post-Olympics the 'assessment as to whether any proposed benefits have been realized is limited' (Cashman, 2002, p.7). This research will therefore allow empirical data to materialise, in order to enhance the sparse literature base (Pappous and Camps, 2013; de Souza and Pappous 2013). This will provide strong evidence 


\section{A. S. Pappous and E. J. Hayday}

into the effectiveness or ineffectiveness of two NGB's legacy plans, regarding participation and the engagement of the organisation and capitalisation on the mega-event itself. Furthermore, by utilising the qualitative interview data alongside the membership figures for both Judo and Fencing, trends and perceptions regarding perceived success and failures, in terms of a community participation changes can emerge.

Relating to the economic cost of hosting mega sporting events, Frawley and Cush (2011, p.65) argue that considering the vast quantity of public money that is spent on hosting the events, it is important to critically investigate and evaluate their effectiveness in increasing PA and sport engagement. To date, the execution of this recommendation by previous megaevent hosts has been predominately inconclusive or largely based on opinions and estimations, rather than empirical evidence. A recent study evaluating the 2000 Sydney Olympics highlights the legacy of the Games may be evident through urban developments such as new infrastructure, however verification of such a mega-events impact on PA remains elusive (Bauman, Bellew and Craig, 2014). Grix (2014) reinforced the idea that there is limited evidence to support the reality of many mega-event hosts 'hoped-for' legacies and that current evidence is poor as previous Olympic and Paralympic Games have used generic measures of social impacts, which has resulted in incomprehensible evidence regarding the changes to health and PA (Weed et al, 2009).

The UK government and the London 2012 Organising Committees aim to 'Inspire a Generation' and increase the number of individuals engaging in grass-root sport and PA, was an ambitious objective. As the UK Government were attempting to transform a dramatic proportion of the population's attitudes, beliefs and perceptions toward sport, health and PA to successfully implement and sustain the legacy promise. The 'trickle down or demonstration' effect, has been proposed extensively to rationalise and justify the benefits of hosting mega sporting events such as LOPG (Hogan and Norton, 2000, DCMS/Strategy Unit, 2002, Hanstad and Skille, 2010). Nevertheless, as early as the 1990's, complications and issues with the trickle-down effect were highlighted by Hindson, Gidlow and Peebles (1994). They concluded that the 'trickle down' phenomenon is not a certainty, like it is still commonly promoted in connection to mega sporting events. Yet, it is advised that the Olympic and Paralympic Games could be used as a catalyst, to support long term strategies and planning aiming to increase participation rates (Hindson, Gidlow and Peebles, 1994). Murphy and Bauman (2007) reinforced these concerns as post the 2000 Sydney Olympics participation rates actually dropped, with individuals participating in less PA than two years prior to the Olympic Games. Pappous (2011) echoed these findings, through an investigation 


\section{A. S. Pappous and E. J. Hayday}

on Athens 2004, his results proposed a rebound effect had occurred. Thus instead of a sustainable participation increase, a short lived spike occurred followed by a fall in participation with a decrease in non-exercisers from $75 \%$ to $57 \%$ post-Olympics. Consequently, these studies contradict the suggested trickle-down effect, which has been used by many nations as a major justification to reinforce the hosting of a mega-sporting event. Nevertheless, as an alternative, Weed et al. (2009) proposed the 'festival' effect as a more beneficial way to engage sedentary individuals, as the 'trickle down' effect is mainly advantageous for individuals already positively engaged with sport and physical activity. Grix and Carmichael (2011) in their effort to address the complex relationship between elite and mass sport participation coined the concept of a'virtuous cycle' in which 'elite success on the international stage leads to prestige and elite sport contributes to a collective sense of identity; this, then, boosts a greater mass sport participation, leading to a healthier populace; this, in turn, provides a bigger pool of talent from which to choose the elite stars of the future and which ensures elite success. The process then starts over again' (p. 76). In fact, Grix and Carminchael (2011) expressed their scepticism in regards to the validity and transferability of this East European model of sporting success to the specificities and the cultural context of the UK. Finally, one of the main methods, in which to increase grass-root participation is through schemes and programmes, which were created and implemented by the NGBs of each sport.

\section{National Governing Bodies}

NGB's were first created around the $19^{\text {th }}$ century, as voluntary organisations and they play a dominant role in supporting sports development in the UK (Green, 2008). Specifically, 'from a governance perspective, NGBs are non-profit organizations, managing both professional and amateur sports, and administer the allocation of considerable amounts of funds, especially public funds' (Taylor and Sullivan, 2009, p.681). NGB's of sport remain at the core of Sport England's strategies and sports development aims focusing on helping more individuals in the UK, to undertake a sporting habit for life (Sport England, 2014a). Eligible NGBs that are recognised by Sport England submit Whole Sport Plans (WSPs) every four years, which states how they plan to increase the number of individuals participating in their sport once a week (Sport England, 2014a). Many researchers in recent years have begun to analyse organised sport and the role of NGB's, to investigate the changes in membership pre and post a mega sporting event. This allows analysis of the impact, if any, that a mega events has had on grass-root participation (Frawley and Cush, 2011; Veal, Toohey and Frawley, 


\section{A. S. Pappous and E. J. Hayday}

2013). In 2008, Girginov and Hill's addressed the connection between hosting the Olympic Games and sports participation in the host country, using a process-oriented approach. They reviewed the processes involved in envisioning, framing and implementing an Olympic legacy and found that attaining sustainable participation remains achievable, but the International Olympic Committee (IOC) and the UK government are influential organisations that can apply substantial impact on sports development, through emphasising it on their agenda and directing resources effectively (Girginov and Hills, 2008). This to date has not occurred, accentuating the questionability of this ambitious aim to improve a nation's PA level, as early as 4 years prior to the London Games. Taks et al (2014) investigated the sports development outcomes of the Pan-American Junior Athletics Championships. They suggest 'future research should focus on the underlying processes, rather than just the impacts and outcomes' (Taks et al, 2014.p.213), strengthening the relevance and need for this current research. In which the processes and attitudes of two NGBs and their subsequent voluntary clubs will be investigated, in alignment with the UK governments and Sport England's objective of increasing participation through NGBs and voluntary clubs. Yet, it is worth noting historically, clubs have displayed indifference towards national objectives, as many volunteer for their love of the sport, which may lead to possible issues in the NGBs ability to achieve an increase in sports participation through this method (May, Harris and Collins, 2012).This research sits within an emerging field, which has developed through the current emphasis and importance placed on legacy and more specifically the role that NGB's and sports federations alike, play in achieving such sports development and policy objectives.

\section{Judo and Fencing}

These two sports were chosen as they are non-traditional UK sports, allowing a wider literature and research base to develop, incorporating these lower popularity sports. As well as analysing the impact that a multi-sport, mega-event had on their grass-root participation levels. In the latest Active People Survey (APS) ${ }^{1} 7$ (2013), participation rates in these two Sport England funded sports were recorded for the period April 2012- April 2013. Participation once per month, in Judo equalled 30,700 individuals, whilst 20,900 participated in Fencing. Comparatively, the nation's most prevalent monthly participation rate was seen in swimming, which attracted just fewer than 5,000,000 individuals during the period. This

\footnotetext{
${ }^{1}$ The Active People Survey continuously measures the number of people taking part in sport across the nation and in local communities. It is the largest survey of sport and activity ever carried out in Europe and TNS-
} 


\section{A. S. Pappous and E. J. Hayday}

reinforces the limited engagement by the nation in both sports, which provides an interesting outlet to evaluate if the largest global sporting event, the Olympic and Paralympic Games had any influence in increasing the profile and participation rates in these sports. There is a lack of preceding research focusing on lower prevalence sports and the potential catalyst effect that a multi-sport, mega event could have in relation to participation growth, thus this investigation will provide some of the first findings for this phenomena.

\section{Methodology}

The two main research questions that this paper tried to address were:

-Have the London 2012 Olympics had an effect on the participation rates within Judo and Fencing in the host country?

-How did they aim to achieve this?-Investigation into the mechanisms and processes that were used within the NGBs.

This study used a mixed methods approach; incorporating both qualitative and quantitative data to effectively answer the research question. This methodology choice is strengthened by Nau (1995, cited in Gratton and Jones, 2004, p.25) who claimed that 'blending qualitative and quantitative methods of research produces a final product, which can highlight the significant contributions of both'. The theoretical framework for this study was critical realism, where it is believed that the social world is comprised of four modes of reality: material, ideal, artefactual and social and it is this unique feature in which multiple modes of reality exist for all phenomenon under investigation (Byers, 2013, p.10). The identification of these modes reflect the multi-faceted, complex nature of mega-events and possible legacy implications, where the 'social' mode for example relates to unplanned social structures and casual powers such as norms and rules, which all play there part in the grass-root participation process (Fleetwood, 2005). Looking through the critical realist lens, structures and agents are seen as factors that combine to determine the outcomes of social phenomena (Byers, 2013, p.11). Thus, the mechanisms could not be understood through the structures alone, investigation into the influential agents was needed, highlighting the importance of undertaking interviews both at the NGB head office and within the voluntary clubs themselves.

Case study method is favoured when asking 'how' and 'why' as part of the main research question and when an in-depth, thorough understanding of the social phenomenon is needed (Yin, 2014). They can be split into single or multiple case designs, yet multiple-case research is often regarded as more robust and for this research provided an opportunity to use a 


\section{A. S. Pappous and E. J. Hayday}

multiple-case, replication design to investigate two non-traditional English sports with similar characteristics (Yin, 2014). Interviews and document analysis were used to explore the selected phenomenon in this case study (Baxter and Jack, 2008) and the epistemological status of the case study was exploratory, resembling a pilot study, allowing the researcher to gain insight into the structure of the phenomenon and subsequently a model or theory to be developed (Scholz and Tietje, 2002). As these multiple cases are investigating more than one unit of analysis, through the exploration into the quantitative membership figures, as well as interviews with both the NGB head office and the clubs themselves, an embedded case design was used (Scholz and Tietje, 2002). Critical realism is well suited to case study research as it justifies the study of any situation, regardless of the number of research units, but only if the process involved in-depth well thought out research with the objective of understanding why things are as they are (Easton, 2010).

\section{Quantitative Methods}

Similarly, to Frawley and Cush's (2011) research, this investigation follows a case study approach and utilised the registered membership data from the NGBs of each sport, the British Judo Association (BJA) and the British Fencing Association (BFA). The importance of using the membership data relates to the dominance of participation that occurs in the club environment for these two sports. $59 \%$ of Judo participation and $50 \%$ of fencing participation occurred in the club environment, which if compared to swimming, only $3 \%$ of participation is undertaking in the club environment (Sport England, 2014b ${ }^{2}$ ). The nature of judo and fencing requires specialised equipment, training, coaching and insurance leading to a higher proportion of club based participation and memberships.

Many apprehensions of over or under recording have been raised, and this was considered, with regards to the reliability of participation data, which in many cases is self-reported. Yet, specifically focusing on the judo and fencing statistics, this study used the registered membership data which is rich, empirical data specifically from the NGB's database. Frawley and Cush (2011, p.72) highlighted that membership data 'does not indicate the frequency of participation, only the number of people registered from a sport'. As individuals may be registered with a NGB or sports federation however do not participate for multiple reasons such as injury, thus this issue was considered when analysing the data.

\footnotetext{
${ }^{2}$ Club Membership Figures averaged from the available APS club membership data sets (APS 2,3 and 4)
} 


\section{A. S. Pappous and E. J. Hayday}

Qualitative Methods

The semi-structured interviews undertaken focused on individual's experiences and attitudes towards the LOPG and the impact this had on their specific sport. The interviews were conducted with club volunteers and coaches, as well as individuals based at the NGBs head office in the respective sports ${ }^{3}$. In fencing 6 interviews were conducted with club volunteers and coaches and 2 with the BFA, and in judo 5 interviews were undertaken in the club setting and 2 with individuals from BJA. The interview guide was created through three methods. Firstly, existing literature was reviewed to identify key themes such as communication, club engagement, available resources and public contact with elite sport through the media for example (Girginov and Hill, 2008, Frawley and Cush, 2011; May, Harris and Collins, 2012). Document analysis was then undertaken with BJA and BFA's WSP's and annual reports, which provided relevant data and information regarding the specific strategies and programmes that both sports implemented, allowing the interview guide to be tailored with these characteristics in mind. Then an exploratory focus group was undertaken, as a pilot study with individuals working in the voluntary club environment, which allowed any additional content to be added and existing content adapted based on their experiences. This lead to the creation of the interview script, which was subsequently tested by two academics that specialise in Olympic Studies, the focus group and testing phase allowed any issues with clarity and content to be identified and corrected prior to data collection.

Data analysis was undertaken inductively through open and axial coding, using Corbin and Strauss (1990) approach, to allow the identification of key themes to emerge in the data analysis phase. As Greetham (2009, p.181) states that qualitative data 'describes attitudes, feelings, opinions and beliefs,' providing an acute examination into the volunteers, coaches and NGB's perceptions and views. These are the organisations and individuals on the front line delivering the grass-root participation to the nation, hence the results provide valuable and advantageous insights into the strengths and challenges that clubs and NGBs face within the English sports system, through this case of two non-traditional sports. This will provide future mega-event hosts and policy makers with a greater understanding of the context and multi-faceted nature how you implement and aim to achieve such an objective.

\footnotetext{
${ }^{3}$ Note- Quantitative membership data provides a UK wide picture, however interviews with both the BJA and the BFA where undertaken within England only.
} 


\section{A. S. Pappous and E. J. Hayday}

$\underline{\text { Results }}$

Quantitative Results: Judo and Fencing

The table below highlights the figures provided by the BJA, for UK membership. Judo memberships shown in Table 1 include both 'renewed' and 'new' memberships, for the three main membership categories 'Junior, Senior and Recreational'.

\section{Table 1 here:}

The table highlights that between 2007 and 2013 there has been a consistent increase in national memberships, overall an increase of $13.6 \%$. Yet, there was a slightly stale period in 2010-2011, in which membership increases dropped to (+0.03\%). Membership started to increase steadily again in the final lead up to the LOPG. Post London 2012, overall memberships were recorded at the highest ever level 26,154 members, with overall increases seen, year on year, since 2007 (oldest data set received). This increase in 2012-2013 (+4.4\%), equalled a state similar seen in 2008-2010, with just a slight greater increase of $0.2 \%$, from the previous highest annual membership increase of $4.2 \%(23,590$ members $)$ in 2008 . However, looking at the plateau shown in 2010-2011, the post-Olympic (2012-2013) increase was $4.4 \%$, highlighting a successful reboot in BJA memberships.

Table 2 below displays the statistics provided by the BFA, for UK fencing memberships, they include the three main fencing categories: Foil, Epee, and Sabre.

\section{Table 2 here:}

Table 2 focuses on fencing participation and highlights a successful participation increase, between 2007 through to 2013, from 7999 to 9569 members, highlighting a post LOPG increase of $+16.4 \%$. Table 2 shows a diverse range of participation changes across the 20072013 period. Specifically, in 2010-2011, there was a sharp decrease in membership of $14.1 \%$, yet the following year (2011-2012), there is a clear bounce back with a $+13.8 \%$ increase. This increase coincides with the LOPG and the following annum (2012-2013), the fencing memberships were still increasing however this slowed to $+0.6 \%$. Comparatively to 


\section{A. S. Pappous and E. J. Hayday}

Table 1, the membership figures displayed in Table 2 show a more irregular pattern in which larger membership discrepancies, year on year, are evident.

Qualitative Results

Participation

Regarding the qualitative element of the research, findings were diverse with many interviewees focusing on participation and their efforts to capitalise and promoting themselves through the LOPG. The majority of respondents, both club and head office interviewees felt there had been a small but steady increase in participation since the Olympic bid was won in 2005. 'As the games were announced I think people started thinking about sport and it was significant but not a large change to memberships...more of a steady increase' (Respondent 2- Judo). 'We promote all the time, constantly trying to find new beginners...for us, yes, probably we are unusual, we noticed an increase in participation' (Respondent 4- Judo).

Judo respondents identified that the largest participation increases were seen through returning participants, the BJA head office identified the increase in this sector as 'we tracked returning members... I would say around 150 returning members' (Respondent 6- Head Office Judo). Additionally, many head coaches identified the same trend 'we had adults encouraged back into it because of the Olympics' (Respondent 1-Judo). The 'biggest percentage increases' have been returning players and 'we have quite a few females coming back from 20 years ago and now they are bringing their kinds' (Respondent 3 and 5-Judo).

Yet, some interviews revealed that many clubs did not take advantage of and engage with the LOPG enough to promote their club to increase participation. Thus, this lack of engagement could explain the detachment expressed by the some interviewees, to the possible gains that a mega sporting event is suggested to provide, which may have limited uptake to some clubs. ' $I$ didn't use any programmes or activities to promote my club' and there was 'no massive difference' in the number of participants (Respondent 3- Fencing). However, one interview highlights that there is an 'adaption period' (Respondent 3- Judo), when capitalising on a mega-event to work out the best strategy. 'The Olympic Games will not happen here any time soon, we had to use it... we started just before the Olympic Games and were not that successful but once it started, we were totally full' (Respondent 4- Fencing) 


\section{A. S. Pappous and E. J. Hayday}

Also many interviewees were unsure on the specific participation changes since 2005, due to the length of time since the LOPG bid was won. Additionally, a lack of memory and hesitation surrounding post LOPG changes in participation was seen, as due to the early time scale of the research, many clubs were as yet, unsure of the post-Olympic and Paralympic trends, as they are still emerging. 'Our memberships are more or less the same, but give us another year and we will see because we have much bigger access to people because we can get into the schools' (Respondent 2- Fencing), highlighting use of school programmes to attract members.

\section{Grass-Root Participation Programmes}

The grass-root participation programmes where mentioned throughout the interview processes, with many of the echoing the idea that the 'programmes themselves played a greater importance in increasing participation levels' (Respondent 1-Judo), as 'the taster sessions were important in local schools' (Respondent 1- Fencing) and these were identified as more important in changing participation, than the hosting of the LOPG themselves. The 'Olympics helped us to open those opportunities...but we need to catch young people, through the Youth Games programme sponsored by Specsavers ${ }^{4}$ - promoting fencing, parents see fencing, children can try it and everyone sees the enthusiasm and passion' (Respondent 2- Fencing).

These responses highlight the importance of the grass-root level initiatives rather than the reliance on the demonstration effect to bring in new members to both Fencing and Judo. Yet, the odd problem with the programme implementation and effectively delivery was raised, as an interviewee said I saw a 'participation increase, I wouldn't say sudden but definitely gradual, some schemes we has trouble with travel management and a wide ethnic diversity, culture problems, as in east London is sometimes too dangerous for kids'(Respondent 4Fencing). Also a critical issue was identified by the head office and the coaches with the exit route from the school programme, this transition is critical to ensure sustained participation can be achieved from a programme. But 'the kids were retained on the site and there was no transition, the coaches on that scheme were based on membership stats...there was no

\footnotetext{
${ }^{4}$ The Specsavers Youth Games is an inter-parish sports competition for teams and individuals, the principle aim of the Games is to promote the value of sport to the young people and provide the feeling of participating in a large-scale sporting event (Guernsey Sports Commission, 2013)
} 


\section{A. S. Pappous and E. J. Hayday}

incentive for them to bust a gut trying to get them to the club' (Respondent 6- Head Office Judo).

'We have had success with Judo at schools in breakfast and afterschool clubs linking to an Enjoy Judo coach. We run it not as part of the legacy but a specific programme for in primary schools, however the transition from the school Judo to the Local clubs is difficult as the young children want the same coach and ask 'are you going to be there' (Respondent 2- Judo)

\section{Media and Promotion}

The media was highlighted as a vital catalyst and was suggested as a reason for the successes and participation increases nationally, by many interviewees.

'Athletes portrayed as idols and local champions for the population,' through the media (Respondent 4- Fencing). Additionally, media coverage ensured heightened awareness with clubs receiving 'more hits on our website, as people are checking what fencing is all about' (Respondent 5- Fencing) and 'some people who had never seen fencing before... media made a massive difference'(Respondent 6- Fencing). Also we had '3 Olympic fencers at our club around the time of the Olympics, at an open day with free food, it worked well' helping to boost the awareness and sign ups (Respondent 2- Fencing).

This club marketing and promotion undertaken by most fencing clubs, was not echoed through the Judo interviews, data revealed that few of the respondents incorporated Olympic themed promotion into their clubs or local area. 'During the games we didn't make any particular effort for a drive in players, but we updated our website and Facebook page just before the games' (Respondent 5- Judo). We didn't do 'much at a club level... we did try to push stuff on Facebook' (Respondent 2- Judo). Both interviewees even though they did not feel they undertook a lot of promotion, both utilised web sources and social media highlighting its use by NGB's as promotional tool. Similarly an established head coach in fencing was disappointed with the national media efforts, as it continues to astonish me, how poor we are at pushing our sport... we are not good enough yet as getting right out there and telling people about our sport' (Respondent 4-Fencing). Overall the limited promotion and capitalisation on the LOPG by some of the clubs, could have affected the opportunity to increase membership rates in a time when a vast proportion of the population were in the LOPG mind-set and may have shown responsiveness to increased media efforts and local 


\section{A. S. Pappous and E. J. Hayday}

awareness. This suggests a possible lack of planning by the local clubs and maybe an absence of guidance from BJA and BFA, especially for some of the less proactive clubs of how to increase participation.

\section{Miscommunication between NGBS and Local Clubs}

Through both the fencing and judo interviewees, there seemed to be a lack of communication between the NGB's and the local clubs. When interviewees were asked about their knowledge of the vast range of programmes available to the sports ${ }^{5}$. A typical response was:

'No, I have not heard of that programme' (Respondent 3- Judo), this was echoed in some fencing clubs, as some 'don't recall anything constructed to promote minority sports such as fencing' (Respondent 5- Fencing) and 'not aware of any programmes specifically for fencing' (Respondent 6- Fencing). This reinforces a lack of communication and knowledge between the NGB and clubs but also the clubs themselves, as 'all the clubs are doing their own thing, there is no combined effort' (Respondent 1- Judo), reinforcing the need for stronger communication and knowledge. This lack of communication across the NGB system and a feeling of limited knowledge was voiced by all judo Respondents, and by 2 of the fencing interviewees.

Some interviewees were aware of the programmes put in place by the NGB, however they reported the bureaucracy and logistical issues involved in order for their club to participate in these schemes discouraged them from applying. Two respondents said: 'it is a good, scheme, but there is too much paperwork... and all that additional time and effort from the volunteers', (Respondent 2-Judo) 'too much unnecessary paperwork and paperwork can kill the enthusiasm' (Respondent 1-Fencing). Those comments highlighted the need to improve communication and knowledge of the programmes and provide assistance to the local clubs wishing to apply. Indeed the interviews carried out with individuals based in the head office (NGB) provided evidence that supports and acknowledges the need to enhance communication between the NGB and the clubs. For example, an interviewee from one of those NGB's involved in the research admitted that: 'There is a communication gap between Sport England and us, and then us to the clubs. Some clubs historically hate us' (Respondent 7-Head office). This was supported by a Head Office interviewee from the other NGB, who

\footnotetext{
${ }^{5}$ Researcher probed interviewees about their knowledge of existing programmes both nationally such as 'Sportivate' and NGBs specific programmes such as 'Go-fence' and 'Enjoy Judo' to gain an understanding of respondents level of knowledge.
} 


\section{A. S. Pappous and E. J. Hayday}

identified that they 'need to engage with the club more and get them to do it rather than us, because ultimately a child is only going to stay in the sport if they like there club' (Respondent 8- Head Office).

\section{Funding and Sport England}

The distributions of public money and its use to sustain grass-root development and the funding system were common themes mentioned throughout. 'British Fencing were awarded over 1 million from Sport England...is coming to us? To grow the sport we need that for clubs at the ground level' (Respondent 5- Fencing). Similarly in Judo, 'any BJA affiliated club is surviving purely because of... volunteers hard work; there is no funding to the clubs from national funding' (Respondent 1- Judo).

'The funding that is going into Judo is going to the elite level. As far as I'm concerned there has been virtually nothing down at the club level, and it is like any tree, if you want it to grow you have to feed it at the root' (Respondent 5- Judo).

This reinforces the detachment that was felt between the national funding received through the NGB and the frustration at the club level where interviewees felt they were not receiving any financial assistance. One interviewee, a head coach at an established club highlighted the fact that he is unable to apply for funding due to the focus on new clubs and participants rather than supporting the existing outlets, possibility limiting the possibility of using the competent and well-known clubs, who have the capability to deal with the increased demand. As the lottery will support new projects and clubs but not existing clubs trying to expand. We have a waiting list, coaches, a venue and people that want... [but not] the equipment...they would not take that into consideration' (Respondent 4- Fencing)

According to the Judo interviews funding issues affected the sustainability of the grass-root

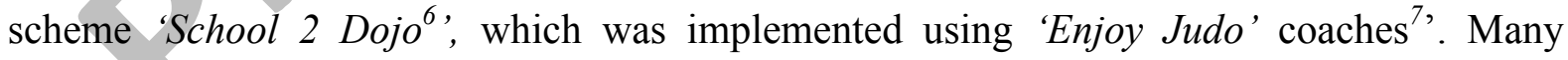
interviewees were angered, as they believed 'due to the lack of funding the coaches were made redundant' (Respondent 1- Judo). 'Why set a target of three medals when we haven't won any in twelve years? I don't know... As we didn't make the target... our funding has been cut and the Enjoy Judo side of it was the first to go' (Respondent 2, 3 and 6- Judo).This

\footnotetext{
${ }^{6}$ BJA's 'School 2 Dojo' programme, is school based and helps BJA clubs to develop active links with their local schools, helping to attract more participants into the community through school-club links (British Schools Judo Website, 2014).

7 'Enjoy Judo' were BJA coaches who delivered judo within schools at the grass-root level, they travel between schools and were known as the 'man in the van' (Respondent 7-Judo Head Office)
} 


\section{A. S. Pappous and E. J. Hayday}

echoes the limited and miscommunication previously described between the NGB and local clubs.

\section{Discussion}

In both Judo and Fencing, 2010-2011 provided the weakest year in membership figures. When investigating these changing the importance of incorporating a qualitative element to allow exploration of these changes is vital. For both Judo and Fencing the communication with the head office was essential to help shed light on these figures. In Judo, it is worth noting the lower increase in memberships between the 20102011 period could be explained through a variety of reasons. The qualitative data drawn from the semi-structured interviews with the BJA head office and Judo coaches indicate that, firstly the lower increase in memberships could simply be a failure to retain existing members during the course of the year, or failing to encourage individuals to renew their 2 year membership. Or it could relate to a lack of funding to promote Judo itself or specifically a lack of funding to financially support clubs and individuals. Yet, more importantly in this period there was a loss of a scheme within BJA (Respondent 7- Head Office Judo). The original school-based programme changed during this year to the new scheme 'Enjoy Judo'. This change will have taken time to rebuild, attract and engage members, stressing the importance of reviewing the strategy changes that may have occurred within an NGB's approach, to help account for any abnormalities in the data set.

Additionally, the general fluctuations in the Judo membership across the 2007-2013 period could be due to the variety of memberships that are available from the BJA, which can either be purchased for 3 months, 1 or 2 years (British Judo, 2014). Hence, if an individual brought one of the 2 year memberships in 2011, they would not need to renew this member until 2013, which could account for some of the plateau in memberships around the LOPG. Yet, between 2007 and 2013, the results show the membership figures have increased overall by 3,552 members from 22,602 in 2007 to 26,154 in 2013. This increase of $+13.6 \%$, may suggest that the NGB successfully prepared for the LOPG through their participation plans and strategies outlined in their WSP documentation, as increases were seen as early as 2008, and maybe earlier still if access to previous datasets was agreed.

BFA displayed a sharp decrease in memberships (-12.3\%) between 2010 and 2011 (Table 2) and after discussions with individuals from BFA (Respondent 8- Fencing Head Office), two main factors could help to explain this dramatic decrease in memberships. Firstly, BFA 


\section{A. S. Pappous and E. J. Hayday}

stopped a direct debiting system for membership subscription, which caught out a lot of individuals, resulting in their membership expiring, despite the NGB's best efforts to communicate this change to their members. Additionally, in the same period the BFA also launched a new website, which included an online member registration and renewal platform, prior to this memberships were all carried out over the telephone, which caught out a lot of affiliates whilst they adjusted to new site (Respondent 8- Fencing Head Office). This reinforced the importance of media, promotion and technology and how logistical changes even when well communicated can cause dramatic changes to NGBs membership figures. Yet, this diversification and modernisation is needed for NGB's to develop a competitive and user friendly approach, in the long term. Additionally, 'Go Fence' the BFA's main community level participation scheme started in 2010 (Respondent 7-Fencing Head Office) Hence, along with the other modifications to BFA payment and media materials, it could have taken a while to get this new scheme up and running, possibly helping to explain the increase of 1,312 members in the space of one year (from 2010/2011 to 2011/2012).

\section{Grass-Root Participation Programmes}

Both fencing and judo developed and implemented community based programmes during the 'pregnancy period', where programmes need to be capitalised upon to fully leverage a change in PA (Weed et al. 2009). As well as during the LOPG event and beyond, i.e. Go Fence, Enjoy Judo, Sportivate, local taster sessions and School 2 Dojo. Therefore, it could be proposed that the sustained but increase in participation, as highlighted during interviewees and in Tables 1 and 2, may show a relationship between the marketing, promotions and programmes implemented in the effort to increase grass-root participation. The specific issue with the exit route for the BJA's school programme Enjoy Judo, highlights a consideration that is critical when a sports organisation is looking to implement a new youth based programme with objective of transitioning the participants to the local club. As children are hesitant of the transition, without the familiar stimulus of the original coach, thus a practical solution could be to use the funding from the Enjoy Judo to set targets based on transition rates or to use local club coaches to run the sessions to ease the transition to the local club.

Many of the interviewees echoed Girginov and Hill's (2008) concerns of the plausibility all necessary organisations and NGB's to work in harmony and ensure resources are utilised effectively. As interviewees highlighted a lack of knowledge and awareness of programmes and funding, from a NGB level, emphasising the miscommunication between coaches, local 


\section{A. S. Pappous and E. J. Hayday}

clubs and the national organisations. Media appeared to play an important role in the qualitative element in both sports, reinforcing the opportunity that it provided to raise the profile of the sports, as well as the athletes themselves. Discussions suggested that this then had a knock on effect improving knowledge and understanding of the sport, hence, possibly encouraging more individual's to participate. The idea that elite sport inspires grass-root participation, resonances with the demonstration or trickle-down effect (Hogan and Norton, 2000). This identification by Judo interviewees of participation increases largely being formed through returning participants reinforces Weed et al's. (2009) belief that previously positively engaged individuals can be re-stimulated into the sport, through the exposure to the sport that the LOPG provided. Whilst, for new participants the local advertising and programmes had a greater impact, reinforcing the need to use the 'festival' or community elements to encourage engagement from participants previously not engaged with the sport. Yet, interviewee's responses did not specifically shed light on how to engage sedentary individuals. Additionally, many of the fencing interviewees highlighted through the promotion and media coverage, they were able to promote themselves and raise fencings profile locally, to the public. Which links to Weed et al's (2009) 'festival effect', where individuals were initially spectators of the cultural Olympiad, involved with the open day events, but inadvertently became participants, by trying fencing and in turn joining the local club.

The relationship between elite and grass-root funding has caused many misunderstandings by the interviewees. Within the Judo club based interviews, Sport England was particularly targeted with a lot of undesirable connotations relating to the target of 3 medals set for the LOPG and the delivery of funding. Subsequently, as only 2 medals were achieved, common belief was that this shortcoming resulted in a reduction in funding. Yet, the cuts which reached a $40 \%$ reduction for the next funding cycle, where made by Sport England, who are responsible for distributing the finances aimed at increasing grass-root participation to NGB's, including the BJA. Sport England set their participation targets, measured by the APS or additional participation dataset if the sport does not register in size on the APS and Sport England change the funding according in each funding cycle, depending on whether those participation targets have been met rather than through elite medal success, highlighting a detrimental miscommunication on how funding is achieved, between local clubs and the NGB. This mechanism was not acknowledged or understood by club interviewees. Grix and Carmichael (2011) examined the APS, and they suggest that the APS makes it difficult to determine the legitimacy behind claims that the success at elite level filters down and impacts 


\section{A. S. Pappous and E. J. Hayday}

grass-root participation. But due to the pressure of elite based success, NGB's are putting their focus on the elite, rather than ensuring that masses are engagement in sport, which in turn detrimentally affects their funding prospects from Sport England. Carmichael, Grix and Marqués (2012, p.2) highlighted the shift, post-2005 in sports policy, which led to a dramatic change in Sport England's role in policy delivery, who took on a 'new strategic role... to deliver on participation as part of the Olympic legacy'. This in turn caused a 'reliance on NGB's to deliver its targets in the 2008-2013 funding round' (Carmichael, Grix and Marqués, 2012, p.2), causing tension and pressure between these two organisations as critical funding was now at stake, and the interview results above suggest that communication was critical and needs to be improved.

\section{Conclusions}

Membership data suggests that since the Games were awarded to London in 2005, a positive increase in grass-root participation has been seen, in both these non-popular English sports, reinforced that the strategy implemented because of, or alongside this mega-event by NGB's, may have allowed these sports to capitalise on possible benefits believed to be related to such a global sporting event, by promoting and raising their profile. The most unanticipated finding was the discrepancy between the overall positive quantitative results and the misconceptions highlighted in the interviewees between local and national organisations. This again reinforces the importance of coordination between of multiple agencies and indepth strategy planning, or it is unlikely that PA or health legacy will be successful (Murphy and Bauman, 2007). Additionally, in most cases the grass-root programmes themselves were the dominant driving force believed to have increased participation at a local level rather than just the hosting of the LOPG themselves, reinforcing the importance of increasing programme awareness. This limited initial communication, along with the logistical issues involved in funding or programme application caused a knock on effect from which misunderstandings and a lack of programme engagement occurred. Crucially, stronger support and guidance is needed across and between the three levels of the sports system, starting with the national sports council, which in this case is Sport England, but also between the national (NGB) and local level (clubs) of the individual sports themselves. This will ensure the policy objective is able to be fully accessed, understood and implemented by all the individuals involved in the sports development delivery process. Future research, into similar sports would allow a picture to emerge of LOPG's legacy process and achievements within the community sports delivery system, thus strengthening the results from this study. 


\section{A. S. Pappous and E. J. Hayday}

In which some key strengths and weaknesses within the sports delivery system have been identified and provide useful insights for sports organisations with a similar structure on how best to avoid similar communicative flaws and to enhance the opportunities to capitalise on such a large scale event, with the existing structures. In conclusion findings during the conclusive period of this study emphasised the significance of grass-root programme implementation and the need to enhance the delivery and communication within this networks, in order for sports organisations to be able to utilise a multi-sport, mega-event to its full potential. This paper gathered evidence that goes beyond large scale evaluations (Weed et al, 2009; Veal, Toohey and Frawley, 2013) of the sporting impacts of the sporting megaevents by concentrating on the specifics of single sports in order to reveal a richer picture of mechanisms and factors responsible for such impacts. This research has contributed to the enhancement of the current body of Olympic and mega-event literature and provides the opportunity for future, additional studies to build on these preliminary results.

Word Count: 7,580

\section{References}

APS 7 (2013) Sport England Website, Research. Retrieved from: http://www.sportengland.org/research/active_people_survey.aspx

Bauman, A., Bellew, B., and Craig, C. L. (2014) 'Did the 2000 Sydney Olympics increase physical activity among adult Australians?' British Journal of Sports Medicine, bjsports2013.DIO:10.1136/bjsports-2013-093149

Baxter, P., and Jack, S. (2008). 'Qualitative case study methodology: Study design and implementation for novice researchers', The Qualitative Report, 13(4), 544-559. Retrieved from:http://media.usm.maine.edu/ lenny/CAMP\%20SUSAN\%20CURTIS/baxterCASE\%20STUDY.pdf

BBC One (2013) Olympic series 'Inspire' [Online] Retrieved from: http:// www.bbc.co.uk /iplayer/episode/b037n964/Inspire_The_Olympic_Journey_Episode_1/

British Judo (2014) 'Membership Application, Membership Types' [Online] Retrieved from: http://www.britishjudo.org.uk/join/

British Schools Judo Website, (2014) 'British Judo Association School 2 Dojo Programme', [Online]. Retrieved from:

http://www.britishschoolsjudo.com/schools2dojo.php.

Byers, T. (2013). Using critical realism: a new perspective on control of volunteers in sport clubs. European Sport Management Quarterly, 13(1), 5-31.

DOI:10.1080/16184742.2012.744765 
Cashman, R. (2002) 'Impact of the Games on Olympic Host Cities,' University Lecture on the Olympics, Centre d'estudis Olympics (UAB), 1-16. Retrieved from: http://ceo.uab.cat /lec/pdf/cashman.pdf

Carmichael, F., Grix, J., and Marqués, D. P. (2012). 'The Olympic legacy and participation in sport: an interim assessment of Sport England's Active People Survey for sports studies research', International Journal of Sport Policy and Politics, 5(2), 22. DOI: 10.1080/ 19406940.2012 .656675

Corbin, J. M., and Strauss, A. (1990). 'Grounded theory research: Procedures, Canons, and Evaluative Criteria’, Qualitative Sociology, 13(1), 3-21. DOI: 10.1007/BF00988593

De Souza, D. L., and Pappous, S. (2013). Legados esportivos de megaeventos esportivos: uma revisão da literatura. Motrivivência, (41), 42-56. DOI: http://dx.doi.org/10.5007/21758042.2013v25n41p42

DCMS, Great Britain. (2008) Before, During and After: Making the Most of the London 2012 Games. London: DCMS Publicity Unit. [Online] Retrieved from: http://webarchive.nationalarchives.gov.uk/+/http://www.culture.gov.uk/images/publications/2 012LegacyActionPlan.pdf

DCMS/Strategy Unit, 2002. Game plan: A Strategy for Delivering Government's Sport and Physical Activity Objectives. London: Cabinet Office.

Easton, G. (2010). 'Critical Realism in Case Study Research', Industrial Marketing Management, 39(1), 118-128. DOI: 10.1016/j.indmarman.2008.06.004

Fleetwood, S. (2005). 'Ontology in organization and management studies: A critical realist perspective', Organization, 12(2), 197-222. DOI: 10.1177/1350508405051188

Frawley, S., and Cush, A. (2011). 'Major sport events and participation legacy: The case of the 2003 Rugby World Cup', Managing leisure, 16(1), 65-76. DOI: 10.1080/ 13606719.2011 .532605

Gratton, C. and Jones, J. (2010) Research Methods for Sport Studies. London: Routledge.

Gratton, C., and Preuss, H. (2008). Maximizing Olympic impacts by building up legacies. The International Journal of the History of Sport, 25(14), 1922-1938. DOI: 10. $1080 / 09523360802439023$

Greetham, B. (2009) Palgrave Study Skills: How to Write Your Undergraduate Dissertation, New York: Palgrave MacMillan.

Gibson, O (2011, March 29). 'Jeremy Hunt admits London 2012 legacy targets will be scrapped', The Guardian. Retrieved from: http:/www.theguardian.com /sport/2011/mar/28/ jeremy-hunt-london-2012-legacy

Girginov, V., and Hills, L. (2008) 'A sustainable sports legacy: creating a link between the London Olympics and sports participation', The International Journal of the History of Sport, 25(14), 2091-2116. DOI:10.1080/09523360802439015 


\section{A. S. Pappous and E. J. Hayday}

Green, M. (2008) Non-Governmental Organisations in Sports Development. In Girginov, G. (Eds.) Management of Sports Development (89-107). Oxford: Butterworth and Heinmann.

Grix, J. (Ed.). (2014). Leveraging Legacies from Sports Mega-Events: Concepts and Cases. Palgrave Macmillan.

Grix, J., and Carmichael, F. (2012). 'Why do governments invest in elite sport? A polemic'. International Journal of Sport Policy and Politics, 4(1), 73-90. DOI: 10.1080/19406940. 2011.627358

Guernsey Sports Commission (2013) 'Specsavers Youth Games' [Online] Retrieved from: http://volunteer.gg/event/specsavers-youth-games/154

Hanstad, D. V., and Skille, E. (2010) 'Does elite sport develop mass sport? A Norwegian case study', Scandinavian Sport Studies Forum, 1, 51-68.

Retrieved from: http://hdl.handle.net/11250/170845

Hindson, A., Gidlow, B. and Peebles, C. (1994) 'The 'trickle-down' effect of top level sport: myth or reality? A case study of the Olympics', Australian Leisure and Recreation, $4(1), 16-24$.

Hogan, K, and Norton, K. (2000) 'The 'Price' of Olympic Gold', Journal of Science and Medicine in Sport, 3(2), 203-218. DOI: http://dx.doi.org/10.1016/S1440-2440(00)80082-1

May, T., Harris, S., and Collins, M. (2013). 'Implementing community sport policy: understanding the variety of voluntary club types and their attitudes to policy', International Journal of Sport Policy and Politics, 5(3), 397-419. DOI:10.1080/19406940.2012.735688

Murphy, N. M, and Bauman, A. (2007) 'Mass sporting and physical activity events: are they bread and circuses or public health interventions to increase population levels of physical activity?' Journal of Physical Activity and Health, 4, 193-202. Retrieved from: http://repository.wit.ie/id/eprint/111

Scholz, R. W., and Tietje, O. (Eds.). (2002). Embedded case study methods: Integrating quantitative and qualitative knowledge. Sage.

Sport England (2014a). Sports we invest in, NGB Investment. Retrieved from: https://www.sportengland.org/our-work/national-work/national-governing-bodies/sports-weinvest-in/

Sport England (2014b) 'By sport, how do people take part in sport?' [Online] Retrieved From: https://www.sportengland.org/research/who-plays-sport/by-sport/

Taks, M., Green, B. C., Misener, L., and Chalip, L. (2014). 'Evaluating sport development outcomes: the case of a medium-sized international sport event', European Sport Management Quarterly, (ahead-of-print), 1-25. DOI:10.1080/16184742.2014.882370. 
Taylor, M., and Sullivan, N. (2009) 'How Should National Governing Bodies of Sport Be Governed in the UK? An Exploratory Study of Board Structure'. Corporate Governance: An International Review, 17(6), 681-693. DOI: 10.1111/j.1467-8683.2009.00767.x

Pappous, A, S. (2011) Do the Olympic Games lead to a Sustainable Increase in Grassroots Sport Participation? In: Savery, Jill and Gilbert, Keith, (Eds). Sustainability and Sport (pp.81-87). Champaign, Illinois: Common Ground [Online]

Retrieved from: http://kar.kent.ac.uk/31622/1/Book\%20chapter.pdf

Pappous, A. S., and Camps, A. (2013). Evaluación de hábitos saludables en la población donde se desarrollan grandes eventos deportivos. Educación Física, Deporte, Recreación y Actividad Física: construcción de ciudadanías, 166.

Veal, A. J., Toohey, K., and Frawley, S. (2012). 'The sport participation legacy of the Sydney 2000 Olympic Games and other international sporting events hosted in Australia', Journal of Policy Research in Tourism, Leisure and Events, 4(2), 155-184. DOI: 10.1080/19407963. 2012.662619

Weed, M., Coren, E., Fiore, J., Mansfield, L., Wellard, I., Chatziefstathiou, D., and Dowse, S. (2009) 'A systematic review of the evidence base for developing a physical activity and health legacy from the London 2012 Olympic and Paralympic Games', Department of Health. DOI: $10.1177 / 1757913911435758$

Yin, R. K. (2014) Case study research: Design and methods. Sage publications. 